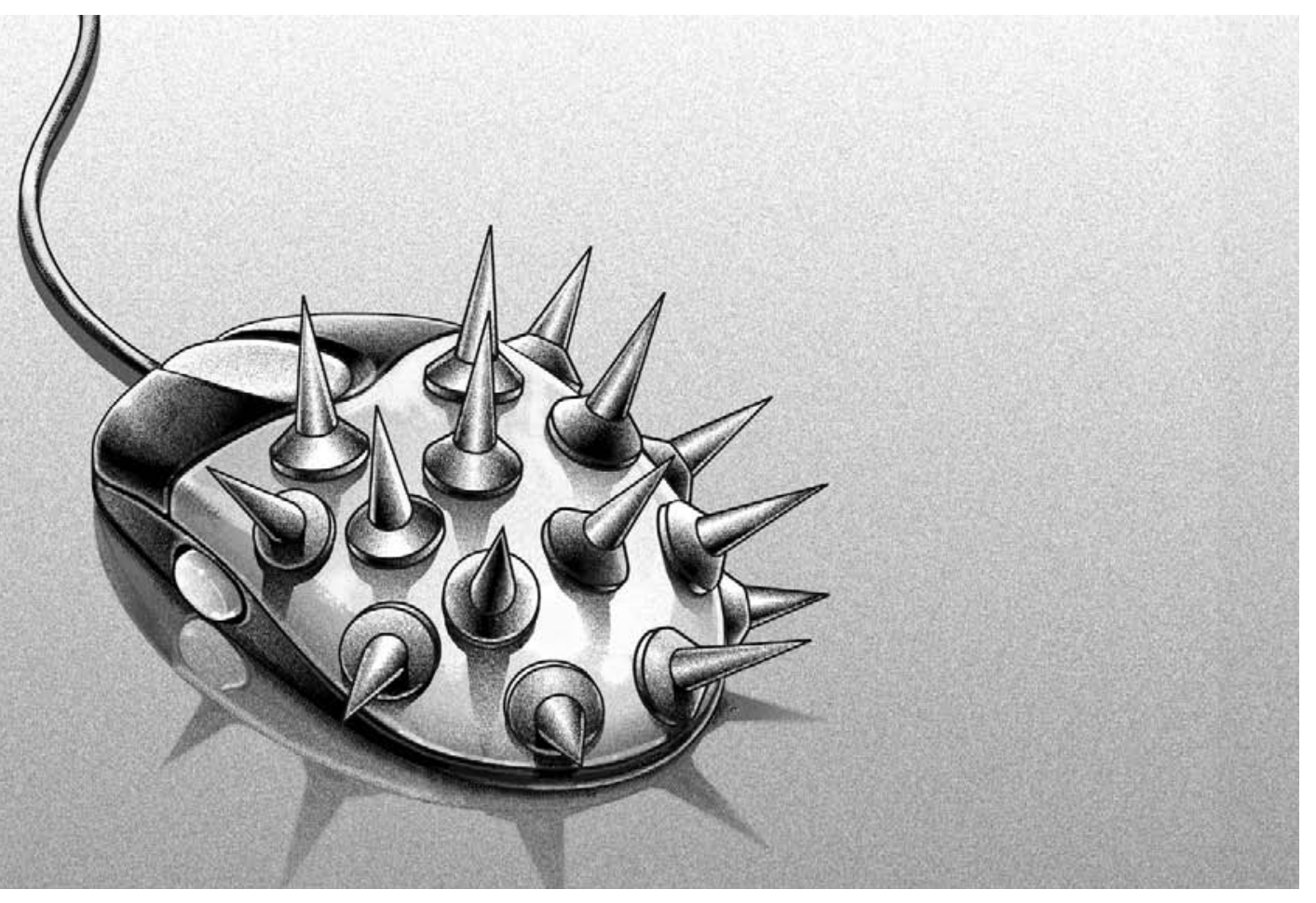

\title{
Crisis 2.0:
}

\section{La necesidad de un modelo integrado de comunicación}

\section{The Need for an Integrated Model of Communication}

Daniel Halpern, PhD program, Penn-State University. United States. (dmh374apsu.edu)

Recibido: $19 / 5 / 2008 /$ Aceptado: 4/6/2008

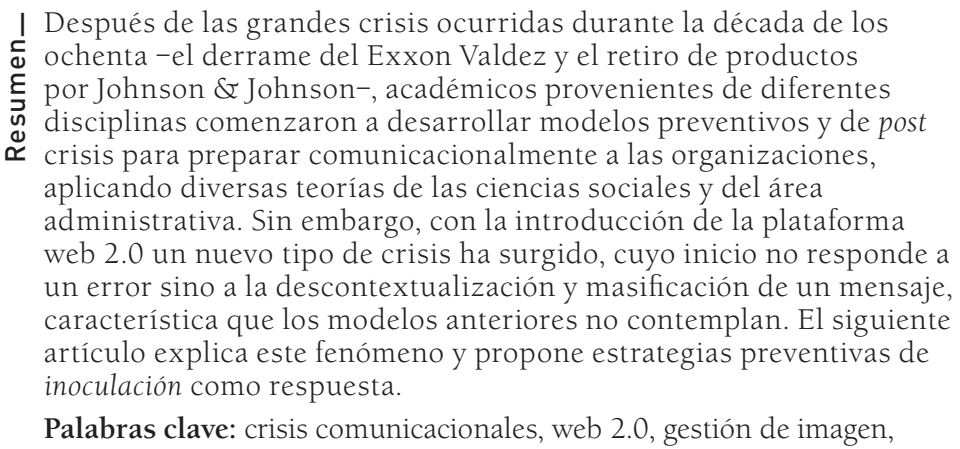

Palabras clave: crisis comunicacionales, web 2.0, gestión de imagen teoría de atribución, inoculación.
I After a series of major crisis during the 1980's, such as the Johnson E Johnson recall and the Exxon Valdez oil spill, scholars from different disciplines began developing communication models to prepare

organizations for crisis prevention and management by drawing on theories

from social sciences and management. With the introduction of the web 2.0, however, a new type of crisis has emerged that arises not from errors, but from the difussion of decontextualized messages. The following article aims to explore this new phenomenon and propose the application of inoculation theory as a proactive strategy of crisis response.

Keywords: Communication crisis, web 2.0, brand management, attribution theory, inoculation. 
D rante más de un año el aspirante a la candidatura el partido demócrata, Barack Obama, evitó referirse al conflicto racial. En estados con mayoría blanca la estrategia había dado resultados, por lo que junto a sus asesores decidieron abstenerse del tema en aras de un mejor posicionamiento (Walters, 2007). Sin embargo todo quedó atrás cuando en YouTube comenzaron a circular incendiarios discursos del reverendo Wright atacando al gobierno norteamericano. El religioso, cercano a Obama, había oficiado su matrimonio y bautizado a sus dos hijas. La crisis estalló y el candidato demócrata tuvo que salir al paso defendiendo el único tema tabú de su campaña. Debió distanciarse de su mentor y responder diciendo que él no pensaba como Wright.

Pero ya era tarde. Más de un millón de personas habían visto cómo el «Reverendo de Obama» acusaba al gobierno de impulsar políticas discriminatorias en contra de la población afroamericana ${ }^{1}$. Sin embargo, ¿fueron realmente las palabras de Wright las que originaron la crisis? Probablemente no, ya que las prédicas habían sido bien recibidas durante las homilías, incluso con Obama entre sus fieles. El conflicto, por lo tanto, estuvo en la masificación y descontextualización del mensaje.

La respuesta no se hizo esperar. En Estados Unidos la opinión pública no perdona y en menos de una semana el candidato demócrata había bajado cinco puntos de promedio en todas las encuestas ${ }^{2}$.

Este es un ejemplo de las crisis 2.0, que, a diferencia de las amenazas tradicionales, presentan una serie de elementos que impiden hacer efectivo el tradicional modelo de respuestas. En primer lugar, las crisis habituales responden a la teoría de atribución de responsabilidades y por ende «estallan» cuando las audiencias creen que la organización respaldó una acción contraria a sus normas y valores (Coombs, 2007). Ello implica que la tipología de respuestas post crisis tradicionales dependa del grado de responsabilidad que se atribuye: mientras menos «culpa» percibe la audiencia que tuvo la organización, más posibilidades tiene ésta en su respuesta de transferir a una tercera parte las responsabilidades para eximirse de lo sucedido (Ulmer \& Sellnow, 2002). La defensa implica que en realidad la acción nunca quiso realizarse, sino que fue una falla y al explicarla, negarla o transferirla -según el grado de atribución como se verá más adelante- la imagen de la organización logra reestablecerse. Numerosos estudios de casos señalan que, si la acción se corrige acorde a las expectativas de la audiencia, la organización puede incluso verse beneficiada (Benoit, 1997).

\section{IMAGEN, IDENTIDAD Y CRISIS 2.0}

De lo anterior se desprenden dos conceptos fundamentales para la gestión de crisis: imagen e identidad. Es necesario, sin embargo, definir ambos elementos antes de explicar la segunda gran diferencia entre las crisis tradicionales y las originadas por la web 2.0.

Imagen corporativa es la impresión generalizada que una organización evoca en la mente de sus públicos, producto de las experiencias asociadas a ella (Brown et al., 2006). Es decir, el conjunto de significados con que las audiencias asocian una organización. La identidad en el ámbito corporativo, en cambio, a su vez está relacionada en cómo la organización se ve a sí misma y la forma en que le gustaría ser percibida (Balmer \& Greyser, 2006). Es decir, la identidad se desprende del conjunto de valores con los que se identifica y diferencia de las demás. Otros teóricos también enfatizan el hecho de que, en cada una de las acciones que realiza, la organización hace una proyección de sí misma. Ésta busca ir acorde a las expectativas que los grupos de interés tienen de ella, en síntesis, intentan ir de acuerdo a su imagen (Fombrum \& Van Riel, 2004).

La interacción de ambos conceptos permite entender por qué en las crisis tradicionales la tipología de respuestas se esfuerza por interpretar el comportamiento de la organización de acuerdo a las expectativas de las audiencias. En otras palabras, toda estrategia de post crisis señala que, una vez analizado lo sucedido, la defensa intenta alinear la explicación del problema y la forma en que realmente se quiso actuar, la identidad, con lo que esperaban los públicos de interés, la imagen.

Y esta es precisamente la segunda diferencia con las crisis 2.0. En los nuevos conflictos el problema es de otra naturaleza, pues el mensaje que lo originó es coherente con la identidad de quienes lo emitieron. Aquí el conflicto no está en el mensaje en sí, sino en la descontextualización y en las nuevas audiencias que el canal alcanzó.
1 Obama's Pastor: God Damn America, U.S. to Blame for 9/11, $(2008,13$ de marzol. ABC News.

2 In Poll, Obama Survives Furor, but Fall Is the Test, (2008, 5 de mayo). The New York Times. 
3 Ver por ejemplo el video "Así Trata Lan Chile a sus Empleados" www.youtube. $\mathrm{com} /$ watch?=3sj $7 \mathrm{ktF} 5 \mathrm{H} \mathrm{Qg}$.
Si bien se profundizará en este concepto más adelante, es importante adelantar que las crisis 2.0 son producto de la difusión de un mensaje que fue ideado para un público íntimo dada la sensibilidad de su contenido, pero que al masificarse afecta la relación con sus audiencias. Tanto éstas como el «afectado» por el mensaje esperaban otro comportamiento. Por esto, bajo los anteriores modelos de post crisis las disculpas podrían perder credibilidad, dado que hubo una clara intención por entregar el mensaje a un público reducido bajo un contexto determinado.

Un tercer punto de desencuentro que tienen ambas crisis son las metodologías preventivas que tanto especialistas como académicos recomiendas utilizar: asuntos públicos y gestión de reputación. Según la tesis de este artículo, ambas estrategias deberían modificarse para ser efectivas en este nuevo tipo de conflictos, dadas las diferencias del contexto en el que emerge cada crisis (Fearn-Banks, 2007). Un ejemplo de esto son los videos en YouTube que afectan a la compañía Lan Chile. Ahí las parodias del vicepresidente ejecutivo de la empresa, Enrique Cueto, comparándolo con Hitler, han sido vistas por más de 200 mil personas y las de su presidente, Sebastián Piñera, acusando maltrato hacia los empleados, por otras 100 mil. Si bien la plana directiva de la compañía no se ha referido al tema, es difícil creer que la exhibición del material realizado por sus propios trabajadores como «bromas» internas no tengan repercusiones negativas para la imagen. Los ácidos comentarios realizados por algunos empleados en las mismas páginas podrían generar al menos cierto resquemor en futuros postulantes ${ }^{3}$. Pero el fenómeno es mucho más amplio. Las groseros comentarios de los panelistas del espacio de farándula Primer Plano hacia su colega Carola Julio, grabados en un celular y posteriormente divulgados por YouTube en diciembre del 2007, desataron un fuerte conflicto en Chilevisión y en el entorno del programa.

Una cuarta y última diferencia es la cobertura mediática. En las crisis tradicionales el rol informativo de los medios está presente desde el comienzo y son éstos los que generalmente destapan el conflicto (Halpern, 2007), mientras que en las originadas por la web 2.0 los medios sólo dan cuenta del conflicto una vez que las audiencias ya se enteraron. Las imágenes de una adolescente practicando sexo oral por ejemplo, alcanzaron 95 mil visitas en menos de 48 horas en la web en septiembre de 2007. Este video recibió mucha más atención que la cobertura que realizó TVN al respecto en su noticiario central. Esto demuestra que, en las crisis tradicionales, el rol de los medios (al menos en una etapa inicial) es meramente informativo, a diferencia de las crisis impulsadas por la web donde este pasa a ser interpretativo, pues deben esforzarse por entregar aspectos novedosos: gran parte de la audiencia está enterada del problema antes de que los noticieros reaccionen. Este aspecto tiene implicancias prácticas para la posterior interpretación del suceso, ya que desde un principio los medios proyectan el marco de referencia -frame- bajo el cual será analizado, condicionando el tema según su línea editorial (Scheufele, 1999).

Finalmente, es importante recalcar que las crisis 2.0 surgen gracias a las posibilidades que ofrecen las nuevas tecnologías, donde no se requieren altos niveles de conocimiento técnico. Hoy en día los usuarios pueden capturar videos y audios de buena calidad a través de celulares, adecuar estas imágenes a un formato atractivo para las audiencias a través de decenas de programas computacionales de edición y posteriormente transmitir el contenido a un público ilimitado por medio de una plataforma web 2.0. Todo este proceso puede tardar menos de cinco minutos. Sin bien hay cientos de alternativas para difundir el contenido, las más populares son sitios de webcasting -transmisión de uno hacia muchos - como YouTube. Otras posibilidades son blogs o redes sociales del tipo Facebook, MySpace o Hi5, las que a su vez también han integrado estas tecnologías. Todos estos sitios permiten que usuarios puedan «subir» videos y archivos de audio libremente, para que luego desde cualquier computador conectado a Internet diferentes audiencias puedan reproducirlos de forma gratuita.

En síntesis, esta nueva clase de crisis podría ser definida como la difusión de un mensaje privado que, dada la sensibilidad de su contenido contra una tercera parte, es capaz de alterar el equilibrio de relaciones que existía con la organización o individuo aludido. Y esa alteración se produce al masificarse.

El conflicto está en el cambio de contexto que sufre 
el mensaje, ya que, si bien en un comienzo es perfectamente compatible con la identidad de la fuente y la imagen que proyecta bajo un público íntimo o reducido, una vez que se masifica ésta se distorsiona desencadenando la crisis. Esta característica, sumada al rol interpretativo y no informativo de los medios al cubrirla, más las falencias que presentan los mecanismos preventivos y de post crisis desarrollados en las últimas décadas para enfrentar estos conflictos, rompe con el modelo de respuesta tradicional y hace necesario explorar otras teorías para desarrollar nuevos paradigmas que respondan a las necesidades del contexto web 2.0.

\section{TEORÍA DE ATRIBUCIÓN COMO GUÍA}

Según autores como Ulmer y Sellnow (2000), toda crisis organizacional es desencadenada por uno o una serie de eventos no esperados y poco rutinarios que generan altos niveles de incertidumbre. Al hacerse públicos, estos provocan que los objetivos de la organización se vean amenazados. Esto se produce porque el evento que lo incitó es de características negativas y, al atribuírsele al afectado, la relación con sus públicos de interés se modifica, lo que obliga a que la organización tenga que alterar los medios que acostumbraba a utilizar para alcanzar sus objetivos (Benoit, 1997). La respuesta frente a esta nueva situación, donde se modifica la previa nivelación de poder que regulaba la relación, es lo que generalmente la gente conoce como crisis (Coombs, 2006).

Lo anterior cobra mayor relevancia bajo el actual sistema de medios, dado que, frente a cualquier problema que se presente, la opinión pública tiene el poder suficiente para cuestionar la legitimidad de las organizaciones involucradas. Además, como toda institución necesita del apoyo o legitimización de sus públicos de interés, si éstas no reaccionan para volver a equilibrar la antigua relación, pueden incluso poner en riesgo su crecimiento o sustentabilidad (Boyd, 2000; Halpern, 2007). Benoit enfatiza el aspecto de responsabilidad presente en toda crisis destacando que, en términos de imagen y reputación, las crisis sólo comienzan cuando las audiencias creen que la organización es responsable por un acto catalogado como negativo (Benoit, 1995). Basándose en la teoría de atribución, la crisis -o el contenido del ataque en contra de la organización- debe te- ner dos componentes:

a) El acusado es responsable por la acción.

b) El acto es considerado ofensivo.

De lo anterior se desprende que una crisis se desata cuando las audiencias creen que la organización o individuo detrás de los actos son responsables. Benoit (1995) señala que las percepciones son más importantes que la realidad y, por ende, el foco comunicacional no recae solamente en el grado de responsabilidad que la organización tiene realmente por los eventos, sino en si sus stakeholders (públicos de interés) y shareholders (accionistas) así lo creen (Lyon, 2006). Este elemento tiene implicancias prácticas para los encargados comunicacionales, ya que junto con solucionar el problema, deben dar cuenta a la opinión pública para así eximirse de responsabilidades y no ver afectados los objetivos de la organización ${ }^{4}$.

La explicación a este fenómeno se encuentra en la teoría de atribución. Weiner (1985) afirma que cuando los individuos se enfrentan a un evento inesperado y de índole negativo, sienten una mayor necesidad de buscar causas que se lo expliquen. Coombs y Holladay (2005) vinculan estas características con las crisis, asumiendo que, cuando un evento cumple con ambas condiciones, es natural que los públicos de interés indaguen las causas de lo sucedido esperando que se asuman las responsabilidades. En términos de imagen, por lo tanto, el problema estaría en cuán atribuible es el acto hacia la organización o individuos responsables, dado que si se los considera culpables puede perjudicar afectivamente la relación con sus stakeholders y consecuentemente ver afectada la reputación (Coombs, 2006).

Esta visión es compartida por gran parte de los autores, por lo que la mayoría de los estudios que hoy se realizan en el área se enfocan en el desarrollo de estrategias de respuesta acordes a las causas que originaron la crisis y al grado de responsabilidad de los actores. $\mathrm{Nu}$ merosas investigaciones demuestran que hay una tendencia a orientar los estudios hacia el impacto que la comunicación post crisis tiene en la reputación de la organización (Lyon, 2006). De acuerdo a Coombs y Holladay (1998), por ejemplo, la respuesta post crisis debería entenderse como un recurso simbólico para proteger la reputación y enfocarse en proteger futuras interaccio-
4 Otros autores como Mitroff (2000) se refieren a este mismo fenómeno pero diferenciando la crisis en el aspecto técnico, que fue la que la originó, y otro comunicacional, definido como lo que sus públicos dicen del conflicto. 
nes que pueda desarrollar con sus audiencias. Es por ello que la defensa debería establecerse en función del tipo de crisis, de la responsabilidad conferida y de las experiencias previas de la organización con sus públicos de interés.

Extendiendo la tipología de restauración de imagen desarrollada por Benoit (1995), Coombs y Holaday (1998) construyeron un modelo de réplicas en el que se identifican siete estrategias de respuestas en función del grado de control que tenía la organización en el momento que sucedió la crisis y, por ende, de la responsabilidad atribuible: a) atacar al acusador b) negación; c) excusarse; d) justificación; e) congraciarse; f) acción correctiva y g) disculpa absoluta.

Además de la retórica de disculpas y de los modelos desarrollados como posibles respuestas, otros autores como Ulmer, Sellnow, Heath y Mitroff (2001) han demostrado que estas estrategias proactivas pueden evitar las crisis o reducir los posibles daños que causarían. Dos grandes áreas se han implementado bajo este enfoque: asuntos públicos y administración de la reputación (reputation management). La primera se relaciona con el desarrollo de programas de monitoreo del entorno e identificación de posibles conflictos para evitarlos antes de su generación. La segunda busca identificar audiencias y segmentar los stakeholders, para crear elementos en común y desarrollar una buena relación con ellos a través de actividades concretas que beneficien a ambas partes y así, basándose en la buena voluntad, disminuir los efectos que una potencial crisis podría traer (Ulmer \& Sellnow, 1995).

Heath y Palenchar (2000) agregan que una buena gestión puede generar tal nivel de compromiso entre la organización y sus públicos de interés que, al alinear sus valores con los de sus stakeholders, estos últimos podrían incluso certificar el buen comportamiento de la organización afectada por la crisis. De esta forma tomarían la figura de garantes -endorsement-, asegurando frente a la opinión pública que las acciones realizadas fueron correctas y que por tanto las responsabilidades atribuidas en términos de imagen no corresponden. Sin embargo, si la relación es débil, lo más probable es que estos grupos le resten su apoyo a la organización, prolongando los efectos de la crisis e intensificando la ame- naza asociada al evento (Ulmer \& Sellnow, 2000).

Una parte importante de los planes de crisis, por lo tanto, requiere de la identificación de grupos de interés y de estrategias para cultivar una relación positiva con ellos. Las organizaciones además deberían establecer políticas de desarrollo social o sustentable para establecer canales de comunicación distintos con sus stakeholders y así construir reservas de buena voluntad, alianzas y entendimiento.

\section{REPUTACIÓN Y CRISIS 2.0}

El principal problema que presentan los modelos de post crisis para enfrentar un conflicto originado por la web 2.0 es que no satisfacen «las necesidades del público en atribuir responsabilidades tras el mensaje», como plantea la Teoría de Atribución (Weiner, 1985). Ello se debe a que los stakeholders simplemente no necesitan atribuirle la responsabilidad del mensaje a una tercera parte, ya que en el propio contenido está el origen de la crisis.

En términos de reputación, el conflicto puede explicarse en base a las expectativas de los stakeholders: dada la imagen que tienen de la organización o de sus miembros, estos esperan una conducta acorde a los valores que representan (Balmer \& Greyser, 2006). Sin embargo, tras ser expuestos a un mensaje contrario a esas ideas, tienden a reaccionar negativamente hacia la organización restándole su apoyo y deslegitimándola.

Para la organización, a su vez, el conflicto es aún mayor ya que no sólo se ve afectada por la pérdida del apoyo de sus stakeholders, sino que además se ve enfrentada a un cuestionamiento de su forma de actuar (Brown et al., 2006). Es decir, a pesar que la identidad de la organización es acorde al mensaje entregado, la imagen proyectada es contraria a sus objetivos (Bromley, 2001). Un ejemplo de ello puede ser la exhibición por la web 2.0 del lenguaje que utilizan los empleados o directorio de una organización durante sus reuniones, discursos o en la rutina del trabajo

Incluso los medios de comunicación internos de la organización o videos «graciosos» entre sus miembros podrían ocasionar serios problemas si alcanzan otras audiencias, dado que en ellos pueden referirse en duros términos a la competencia o realizar bromas contra sus 


\section{En caso de que declaraciones controversiales sean difundidas a través de la web 2.0 , la organización o individuos afectados deberían centrar el foco de discusión en el filtro de información y en las consecuencias éticas y sociales que ello implicó, no en lo que se dijo.}

clientes. Ahora, a pesar de que dicho lenguaje es perfectamente coherente con la identidad y valores de la organización en el contexto bajo el cual se presentaron, una vez que se exteriorizan pueden generar una crisis debido a que la imagen que proyecta difiere de la que sus públicos de interés tenían previamente a su exhibición.

\section{ESTRATEGIAS SEGÚN EL ANTIGUO PARADIGMA}

Acorde a la tipología de respuestas post crisis, la estrategia que debiera seguir cualquier organización afectada por un problema de este tipo se basaría en tres etapas. La primera es el trabajo con los medios. Una vez ocurrido el problema, los encargados comunicacionales propondrían que la cobertura se centrara en el problema social, tecnológico o ético detrás de la propagación del mensaje antes que en el contenido del mismo. Recomendarían la opinión de una tercera parte -endorsementpara intentar desviar el foco de atención y transferirían de esta forma las responsabilidades por lo ocurrido a quien difundió el mensaje. Ello provocaría que se «contextualizara» el problema de acuerdo a la conveniencia de la organización. Por ejemplo, en caso de que declaraciones controversiales sean difundidas a través de la web 2.0, la organización o individuos afectados deberían centrar el foco de discusión en el filtro de información y en las consecuencias éticas y sociales que ello implicó, no en lo que se dijo.

Junto a lo anterior, el canal mediante el cual se intente remediar la situación debiera utilizar también la plataforma web. Además de los medios tradicionales y noticiarios, la web es un mecanismo altamente recomendado por distintos especialistas. Esto, porque ahí no hay intermediarios (gatekeepers) y se tiene la opor- tunidad concreta de interactuar directamente con las audiencias (Holtz, 2002), prevaleciendo el sentido del mensaje original.

Con respecto al contenido de la respuesta, es importante advertir que este debe ser coherente con los cambios que la organización decida emprender dadas las implicancias que el nuevo contexto generó en sus públicos de interés. Lamentablemente, en la gran mayoría de los casos la fuente realmente cree lo que expresó y, por ende, lo más probable es que una disculpa no sea creíble (Lyon, 2006). La acusación de descontextualización tampoco lo exime de responsabilidades, por más que quien masificó el mensaje haya actuado de mala forma. En consecuencia, la única opción factible para mantener su imagen es renegar y retractarse de los pensamientos anteriormente expresados. Sin embargo, muchas veces esta respuesta tampoco es creíble dado a que forma parte de la identidad y personalidad de los miembros de la organización. Es por ello que una vez que estas crisis estallan, se propone buscar otras estrategias.

Con respecto a los métodos de prevención de crisis, tanto el área de gestión de conflictos como de asuntos públicos deberían identificar las posibles amenazas y canales en que los actores participan para intentar reducir su ocurrencia (Luecke, 2004). Como son tantas las posibilidades, el modelo más utilizado por los especialistas es calcular el costo que tendría para la organización, que se evalúa a través de una matriz donde se cruzan variables como el impacto estimado y probabilidad de ocurrencia del hecho. Así se prioriza y se gestiona por etapas. Sin embargo, una vez que la crisis sucedió, este mecanismo no entrega mayores herramientas de respuesta. 
La gestión de reputación en tanto, si bien genera mayores vínculos con los públicos de interés, tampoco incide mayormente en los efectos que una crisis podría generar. Es por ello que es necesario desarrollar modelos de comunicaciones integrados capaces de prevenir eventuales daños a la imagen al verse afectados por conflictos en la plataforma web 2.0.

\section{INOCULACIÓN: TEORÍA Y APLICACIÓN}

La teoría de inoculación se basa en la idea de que tratamientos de refutación, capaces de amenazar las actitudes de individuos, pueden motivarlos a desarrollar argumentos para fortalecer sus actitudes en contra de futuros ataques (Szabo \& Pfau, 1998). Siguiendo la idea de la analogía médica, los tratamientos inoculativos juegan el mismo rol que una vacuna. Las audiencias primero reciben una leve dosis de contraargumentos para que sientan amenazadas sus creencias y luego, producto de la amenaza, los individuos reaccionan protegiendo sus actitudes, lo que los lleva a alcanzar un nivel superior de resistencia frente a futuros ataques (Mcquaire, 1984).

Lumsdaine y Manis en 1953 fueron los primeros en teorizar que los individuos que formaban su actitud a través de mensajes de dos colas -two sided messages-, desarrollaban una mayor resistencia a posteriores estrategias persuasivas (Szabo \& Pfau, 2002). Durante la guerra en Corea, un gran número de prisioneros americanos comenzó a colaborar con el enemigo. Sin embargo, lo que realmente sorprendió a los especialistas fue el hecho de que las traiciones no se produjeron por torturas o amenazas físicas, sino que fueron el resultado de largas conversaciones en las que, una vez concluidas, los soldados renegaban de los valores que su país representaba y por los que ellos luchaban, como libertad, democracia y capitalismo (Szabo \& Pfau, 2002). Después de diversas investigaciones, Lumsdaine y Manis concluyeron que, al igual que muchas ideologías formadas en ámbitos sociales, los participantes tomaban por garantizados los modelos que guiaban su vida sin ningún tipo de cuestionamiento, lo cual los hacía mucho más endebles a amenazas posteriores.

Eagly y Chaiken (1993) demostraron en estudios similares que, tras recibir tratamientos inoculativos, los individuos tienden a reconocer vulnerabilidades en sus actitudes luego de verse amenazados. Esto los motiva a procesar con mayor profundidad la información que reciben, generando sus propios pensamientos sobre el tema. Es decir, al esforzarse por entender mejor la idea detrás del mensaje, terminan fortaleciendo sus actitudes y grado de compromiso. Así, el éxito de los tratamientos inoculativos depende de la motivación y capacidad que presenten los individuos para defender sus ideas (Pfau et al., 1997).

La teoría de inoculación ha sido aplicada en diversas áreas con resultados significantes. En el ámbito de la salud (health communication), por ejemplo, Pfau y Van Bockern demostraron cómo adolescentes bajo tratamientos inoculativos podían alcanzar mayores índices de resistencia ante avisos publicitarios que incitaban a fumar (Pfau \& Van Bockern, 1994). Estrategias de inoculación han sido también utilizadas en la promoción de resistencia a mensajes de ataque político, tanto en campañas (Pfau et al., 1990) como en debates televisivos (Han $\&$ Pfau, 2004). En publicidad, la teoría también se ha aplicado satisfactoriamente como una herramienta para instalar resistencia en públicos de interés y evitar potenciales caídas de apoyo frente a ataques de la competencia (Burgoon et al., 1995).

\section{INOCULACIÓN Y CRISIS 2.0}

La aplicación de tratamientos inoculativos como métodos preventivos de crisis se fundamenta en el hecho de que una «buena dosis» puede fortalecer las actitudes de los públicos de interés frente a posibles ataques externos. Sin embargo, Wan \& Pfau (2004) demostraron que este modelo de prevención es además efectivo por el blindaje que proporciona. Según los autores, la publicidad tradicional se caracteriza principalmente por destacar las fortalezas y atributos de una marca, lo cual produce que las audiencias sobrevaloren lo que la organización realmente es, dejándolas vulnerables a posible ataques.

En términos de imagen y expectativas, esto se explica por el hecho de que, después de escuchar constantemente mensajes positivos y anuncios que resaltan la imagen de individuos u organizaciones, las audiencias podrían crearse falsas expectativas y pecar de exceso de confianza frente a las acciones de éstos. Es decir, po- 
drían esperar mucho más de lo que realmente la identidad de la institución, empresa o individuo son capaces de cumplir. Ello provocaría que al enterarse de algo indebido o inadecuado, el shock sea mucho mayor y el impacto: dada la buena imagen que proyectaba la publicidad de una organización, ésta podría poner en riesgo sus objetivos. Puesto que las audiencias no esperan que una compañía con una buena imagen actúe mal, los efectos de la crisis pueden ser mucho más negativos que en circunstancias regulares.

De lo anterior se desprenden las razones que explicarían por qué tratamientos inoculativos podrían ser efectivos en prevenir al menos el primer impacto que la recepción de un mensaje por la web 2.0 podría ocasionar, específicamente bajo un contexto que no fue contemplado por la organización. Al igual como ha sido demostrado en otras áreas, se espera que audiencias inoculadas perciban menores niveles de responsabilidad en contra de la organización y desarrollen mayores grados de credibilidad hacia esta. Ello generaría menor cantidad de contraargumentos por parte de sus públicos de interés frente a un evento negativo. Un ejemplo podría ser que, tras ver videos que afecten la imagen de la organización en YouTube, las audiencias inoculadas piensen que no son ciertos, que hay una mala intención detrás de quien los subió o que simplemente necesitan conocer la otra parte para evaluar si realmente lo que están viendo es verdad.

En conclusión, este artículo recomienda a los comunicadores corporativos integrar estrategias de inoculación a sus modelos de prevención de crisis, dado que ofrece herramientas capaces de reducir los efectos negativos en caso de que mensajes se masifiquen a través de la plataforma web 2.0. Si bien aún los estudios en esta área son tentativos como para confirmar definitivamente éstas hipótesis, distintas investigaciones demostraron la efectividad de la metodología para prevenir intentos de persuasión, lo cual es perfectamente compatible con potenciales ataques en contra de la imagen de una organización. 


\section{REFERENCIAS}

An, C. Pfau, M. (2004). The Efficacy of Inoculation in Televised Political Debates. Journal of Communication $54,3,421-436$

Balmer J. \& Greyser, S. (2006). Corporate marketing: Integrating corporate identity, corporate branding, corporate communications, corporate image and corporate reputation. European Journal of Marketing 40,7/8, 730-741.

Benoit, W. L. (1995). Accounts, excuses, and apologies: A theory of image restoration strategies. Albany: State University Press of New York.

Benoit, W. L. (1997). Image repair discourse and crisis communication. Public Relation Review, 23, 177-186.

Boyd, J. (2000). Actional legitimation: No crisis necessary. Journal of Public Relations Research,12, 4.

Bromley, D. (2001) Relationships between personal and corporate reputation. European Journal of Marketing, $35,3 / 4,316$

Brown, D. Pratt, P. Whetten, D. (2006) Identity, intended image, construed image, and reputation: an interdisciplinary framework and suggested terminology. Academy of Marketing Science Journal 34, 2, 99-106.

Burgoon, M; Pfau, M., \& Birk, T. S. (1995). An inoculation theory explanation for the effects of corporate issue/advocacy advertising campaigns. Communication Research, 22, 485-506.

Cho, S. \& Gower, K. (2006) Framing effect on the public's response to crisis: Human interest frame and crisis type influencing responsibility and blame. Public Relations Review 32, 420-422.

Coombs, W. T. (1995). Choosing the right words: The development of guidelines for the selection of the "appropriate" crisis response strategies. Management Communication Quarterly, 8, 447-476.

Coombs, W. T. (1998). An analytic framework for crisis situations: Better responses from a better understanding of the situation. Journal of Public Relations Research, 10, 177-191.
Coombs, W. T. (2004). Impact of past crises on current crisis communications: Insights from situational crisis communication theory. Journal of Business Communication, 41, 265-289.

Coombs, W. T. (2006). The protective powers of crisis response strategies: Managing reputational assets during a crisis. Journal of Promotion Management, 12, 241-260.

Coombs, T. (2007) Attribution Theory as a guide for post-crisis communication research, Public Relations Review 33, 135-139

Coombs, W. T., \& Holladay, S. J. (1996). Communication and attributions in a crisis: An experimental study of crisis communication, Journal of Public Relations Research, 8, 279-295.

Coombs, W. T., \& Holladay, S. J. (2001). An extended examination of the crisis situation: A fusion of the relational management and symbolic approaches, Journal of Public Relations Research, 13, 321-340.

Coombs, W. T., \& Holladay, S. J. (2002). Helping crisis managers protect reputational assets: Initial tests of the situational crisis communication theory, Management Communication Quarterly, 16, 165-186.

Fearn-Banks, K. (2007). Crisis Communications: A Casebook Approach (3rd ed.). Mahwah, NJ: Lawrence Erlbaum Associates.

Fombrun, C., \& Van Riel, C. (2004). Fame and fortune: How successful companies build winning reputations. New York: Financial Times Prentice Hall.

Halpern, D. (2007) Los puntos que no mide el rating Cuadernos de Información, 20, 78-86.

Heath, R., Palenchar, M. (2000), Community relations and risk communication: a longitudinal study of the impact of emergency response messages. Journal of Public Relations Research, 12, 2, 131-61.

Holtz, S. (2002), Public Relations on the Net (2nd ed.) AMACOM, London 
Luecke, R. (2004). Crisis Management: Master the Skills to Prevent Disasters. Harvard Business Essentials.

Lyon, L. (2006). Synthesizing crisis communication and reputation management: an experimental examination of memory. Journal of Promotion Management, $12,(3 / 4)$.

Scheufele, D. A. (1999). Framing as a theory of media effects. Journal of Communication, 49, (1),103-/122.

Szabo, E. \& Pfau, M. (2002). Nuances in inoculation: theory and applications. En Dillard, J. P. \& Pfau, M. eds. The persuasion handbook: developments in theory and practice. Thousand Oaks, CA: Sage Publications.

Kamins, M. A., \& Asseal, H. (1987). Two-sided versus one-sided appeals: A cognitive perspective on argumentation, source derogation, and the effect of disconfirming trial on belief change. Journal of Marketing Research, 24, 29-39.

McGuire, W. J. (1964). Inducing resistance to persuasion. Some contemporary approaches. En L. Berkowitz (Ed.), Advances in experimental social psychology, 1, 191-229. NJ: New York Academic Press.

Mitroff, I. (2000). Managing Crises Before they Happen: What Every Executive and Manager Needs to Know About Crisis Management. New York: AMACOM.

Pfau, M., Tusing, K. J., Lee, W., Godbold, L. C., Penaloza, L. J., Yang, V. S.-H., et al. (1997). Enriching the inoculation construct: The role of critical components in the process of resistance. Human Communication Research, 24, 187-215.
Pfau, M., Van Bockern, S. (1994). The persistence of inoculation in conferring resistance to smoking initiation among adolescents. The Second Year Human Communication Research 20 (3), 413-430.

Pfau, M. Kenski H., Nitz, M., and Sorenson, J., Efficacy of Inoculation Strategies in Promoting Resistance to Political Attack Messages: Application to Direct Mail (1990), Communication Monographs; Mar1990, Vol. 57 Issue 1.

Seeger, M. Sellow, T. Ulmer, R. (2001) Public relations and crisis communication: organizing and chaos. En R. L. Heath (Ed.). Public Relations Handbook. Thousand Oaks, CA: Sage.

Ulmer R. and Sellnow, T. (2002) Crisis management and the discourse of renewal: Understanding the potential for positive outcomes of crises. Public Relation Review 28(4), 361-365

Walters, R. (2007). Barack Obama and the Politics of Blackness. Journal of Black Studies, 38, 1, 7-29.

Wan, H., Pfau, M. (2004) The relative effectiveness of inoculation, bolstering and combined approaches in crisis. Journal of Public Relations Research, 16, 3, 301328.

Weiner, B. (1985). An attributional theory of achievement motivation and emotion. Psychology Review, 92, 548-573. 